\author{
Visión Electrónica \\ Más que un estado sólido \\ https://doi.org/10.14483/issn.2248-4728
}

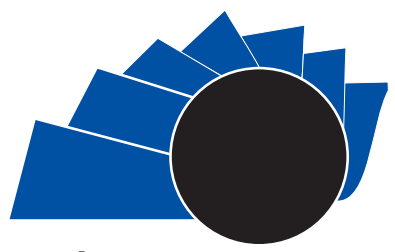

VISIÓN ELECTRONICA

\title{
Wireless prototype for monitoring vehicular parking lots
}

\author{
Prototipo de monitoreo inalámbrico para parqueaderos vehiculares \\ Carlos Iván Córdoba-Lesmes ${ }^{1}$,Brayan Stiven Plazas-Vergaño ${ }^{2}$, \\ Gustavo Adolfo Higuera-Castro ${ }^{3}$
}

\section{INFORMACIÓN DEL ARTICULO}

Historia del articulo

Enviado: 02/11/2018

Recibido: 06/12/2018

Aceptado: 17/12/2018

\section{Keywords:}

Mobile Application,

Parking,

Prototype,

QoS,

Radio Frequency Modules,

Sensor Network.

\section{Palabras clave:}

Aplicación Móvil,

Parqueadero,

Prototipo,

QoS,

Módulos de radiofrecuencia,

Red de Sensores.

\section{ABSTRACT}

This paper describes the development and implementation of a prototype that monitors the availability of space in a sheltered parking lot, establishing quality of service (QoS) parameters. Consequently, radiofrequency modules were used to transmit the information acquired through a network of adapted sensors. The samples taken from the status (available, occupied) are displayed, as well as the data acquired and sent to a web server where they are stored and displayed in a mobile application and the end user can check the status of the parking space, as well as its parking fee, location and structure. Each sensor has an accuracy of $3 \mathrm{~mm}$ ranging between $3 \mathrm{~cm}$ and $4 \mathrm{~m}$, while the radio frequency transmission has a power accuracy of $4 \mathrm{~dB}$ to insure adequate performance.

\section{RESUMEN:}

En el presente documento se describe el desarrollo e implementación de un prototipo que monitorea la disponibilidad de espacios en un parqueadero cubierto, estableciendo parámetros de calidad de servicio (QoS). Para lo anterior, se usaron módulos de radiofrecuencia que transmiten la información adquirida a través de una red de sensores adaptados. Se exhiben las muestras tomadas del estado (disponible, ocupado); así como los datos adquiridos y enviados a un servidor web donde se almacenan y visualizan en un aplicativo móvil donde el usuario final puede verificar el estado de la plaza de parqueo, costo del parqueadero, ubicación y estructura del mismo. Cada sensor tiene una precisión de $3 \mathrm{~mm}$ en un rango de entre $3 \mathrm{~cm}$ y $4 \mathrm{~m}$, mientras que la transmisión por radiofrecuencia cuenta con una precisión de potencia de $4 \mathrm{~dB}$ permitiendo garantizar un adecuado rendimiento.

\footnotetext{
${ }^{1}$ BSc. In telecommunications Engineering, Universidad Distrital Francisco José de Caldas, Colombia. Current position: Cross Border Technology. E-mail: ccordoba@,cbtcyber.com ORCID: https://orcid.org/0000-0001-9320-4704

${ }^{2}$ BSc. In telecommunications Engineering, Universidad Distrital Francisco José de Caldas, Colombia. Current position: TIGO-UNE, Colombia. E-mail: brayan.plazas@asesor.une.com.co._ORCID: https://orcid.org/0000-0001-8534-6841

${ }_{3}^{B S c}$. In Engineering in telecommunications, science and technology, Universidad Distrital Francisco José de Caldas, Colombia. Current position: Professor and researcher of ROMA at Universidad Distrital Francisco José de Caldas, Colombia. E-mail: hahiguerac@uditrital.edu.co. ORCID: https://orcid.org/o000-0001-9691-789X.

Cite this article as: C. I. Córdoba-Lesmes, B. S. Plazas-Vergaño and G. A. Higuera-Castro, "Wireless prototype for monitoring vehicular parking lots", Visión electrónica, algo más que un estado sólido, vol. 1, no. 2, Special edition, july-december 2018. DOI revista: https://doi.org/10.14483/issn.2248-4728
} 


\section{Introduction}

Bogotá and Caracas are the most congested capitals in Latin America and are among the 15 most congested cities in the world. This is shown in INRIX's Global Traffic Table 1, an index that analyses urban journey, traffic conditions and sonority in more than 1,064 cities in 38 countries. According to the latest study, Bogotá ranks six th among the worst rated cities, and is the most traffic congestion one in South America [2].

At present, some projects have been carried out about vehicle control systems and parking meters where it is common to use systems that detect availability by cameras and send the information to a central office [3]. For example, in Santa Fe shopping center, located in Medellin City (Colombia), a parking system that has 28 touch screens is used to see the vehicle's exact location, 2,585 video cameras corresponding to each parking cell, and guide signs, information panels and automated barriers at all vehicle entrances [4]. Another example is the Assistance and Monitoring Systems in open environments that, using artificial vision, are based on an algorithm that uses the information obtained through cameras to determine the state of the parking lot [5].

Conversely, systems that do not use cameras are also common, prototypes that have a monitoring system linked to both a web server in a central station and a mobile application, allowing the user to quickly and easily identify the parking status from a remote location [6]. In [7-10] similar parking systems are developed, such as SMART GPS which is a guided parking system and intelligent parking reservation systems by SMS and SMARTPARKING.

The same way as complete parking systems, it can be identified that algorithmic developments have also been made to determine the location and navigation of the user in urban parking spaces that allow the development of an optimal path to the parking lot [11]; and on the other hand, the development of a mobile detection unit is shown as an alternative to the fixed detection approach, which is assembled on the passenger side of a car to measure the distance from the vehicle to the nearest obstacle on the road. By extracting the characteristics of the parked vehicles, a supervised learning algorithm was developed to estimate the occupancy of the parking lot on the road. [12]

In contrast, and in accordance with current technological advances, where the concept of IoT (Internet of Things) is beginning to be introduced, it can be identified that the search of a parking space is not out this new trend; an intelligent parking system based mainly on the ZigBee and SKY65336 front modules, which seeks to identify the position of the car in real time so that the ZigBee coordinator that is equipped in the parking lot can be updated every second, determining the status of the parking spaces and generating an alert to the previously identified vehicles that can use the available spaces, has been observed in [13].

However, this is not the only system that occurs in the world of IoT; in Australia, a system was developed to transmit sensor node data via a Narrow Band Internet of things module (NB-IoT), which is a new cellular technology introduced for low power wide area applications (LPWA). The modules for basic information management, load management, sensor node monitoring, task management and business intelligence are deployed on the cloud server, which, with the help of the integrated third-party payment platform and parking guidance service, makes the mobile application developed for drivers easy and convenient to use, mitigating the haste to detect an available parking space, [14].

For all of the above reasons, the objective of the present investigation is to create a prototype that generates a differential factor in the provision of parking identification service, allowing the user to locate a parking lot available from their mobile phone, as well as its parking fee.

Consequently, the proposed alternative is based on a network of ultrasonic sensors connected to a radio frequency system using a helical antenna; this proposal is consistent with the reliability criteria mentioned in [15]. At the end of the antenna, there is a small diode that causes the NRF25LO1 ultrasound module to emit a radio signal in response to the radio signal it receives [6]. It has a control system in charge of managing, arranging, directing and regulating the system's behavior in order to reduce the chances of failure [16]. The obtained data are sent to a MySQL database that allows the arrangement, distribution and distinction of the collected data, in order to be displayed in the mobile application; this arrangement is based on the models mentioned in [17], which seek to reduce the complexity of display of data to the end user.

The structure of this document is as follows, in the first section after the introduction that describes the state of the art of technologies currently being developed for vehicle parking lots and the proposed prototype is sketched. In section 2, materials and methods for the proposed system are presented and it is where the stages and quality of service tests are established; in section 3, the results obtained from these tests are illustrated and the parameters to guarantee a differential factor in the 
service are defined; and finally, and in section 4, the conclusions of the research are presented.

\section{Materials and Methods}

In accordance with the difficulties, a system is proposed to optimize parking in the city. The already stated system is made up of a network of sensors that allow detecting the position and location of the vehicle by defining whether or not the parking space is occupied; they are also capable of transmitting this information to a central microcontroller that sends the information through the network to be displayed by a mobile application.

Each sensor consists of three devices: a detector that captures the signal from the environment, a microcontroller that interprets these signals and then turns them into information and an antenna that allows the data obtained to be transmitted wirelessly.

As for the detector, 4 different sensors were compared as shown in Table 1.

\begin{tabular}{|l|l|l|l|}
\hline \multicolumn{1}{|c|}{ Sensor } & $\begin{array}{c}\text { Price per unit } \\
\text { (USD) }\end{array}$ & Sensor type & Distance range \\
\hline CNY70 & 0.51 & Infrared & 0,3 to $0,5 \mathrm{~mm}$ \\
\hline HCSR04 & 1.71 & Ultrasound & 2 to $450 \mathrm{~cm}$ \\
\hline GP2Y0A02YK0F & 11.27 & Infrared & 20 to $150 \mathrm{~cm}$ \\
\hline E18-d80nk & 6.15 & Infrared & 3 to $80 \mathrm{~cm}$ \\
\hline $\begin{array}{l}\text { Load Cell } \\
50 \text { kg Ssdielect }\end{array}$ & 3.76 & $\begin{array}{l}\text { Force- } \\
\text { Weight }\end{array}$ & N/A \\
\hline
\end{tabular}

Table 1. Sensor comparison. Source: own.

A price-to-earnings ratio is used to choose the HCSR04 ultrasound sensor, which measures at a greater distance but at a lower cost.

Regarding the microcontroller selection, 4 chips from different families were compared as shown in Table 2.

\begin{tabular}{|l|l|l|}
\hline \multicolumn{1}{|c|}{ Microcontroller } & \multicolumn{1}{c|}{ Price (USD) } & \multicolumn{1}{c|}{ Family } \\
\hline ATMEGA 328PU & 3.42 & Arduino \\
\hline Pic18f26k20 & 6.49 & Pic \\
\hline Cy8c27443 & 6.83 & Psoc 1 \\
\hline Cy8ckit-059 & 18.79 & Psoc 5 \\
\hline
\end{tabular}

Table 2. Microcontroller comparison. Source: own.

The Arduino ATMEGA was chosen for its simplicity, price and compatibility. Finally, Table 3 shows the comparison of 3 wireless antennas.

\begin{tabular}{|l|l|}
\hline Antenna & $\begin{array}{l}\text { Unit price } \\
\text { (USD) }\end{array}$ \\
\hline NRF24LO1 & 5.12 \\
\hline HC 06 & 5.12 \\
\hline Esp8266 & 4.78 \\
\hline
\end{tabular}

Table 3. Wireless module comparison. Source: own.
The NRF24LO1 Transceiver was chosen because it allows 6 different channels to be used, reducing interference and improving the quality of the service, which warrants the bandwidth used is sufficient for the correct transmission of data, avoiding the its loss.

The block diagram of the proposed alternative solution is shown in Figure 1.

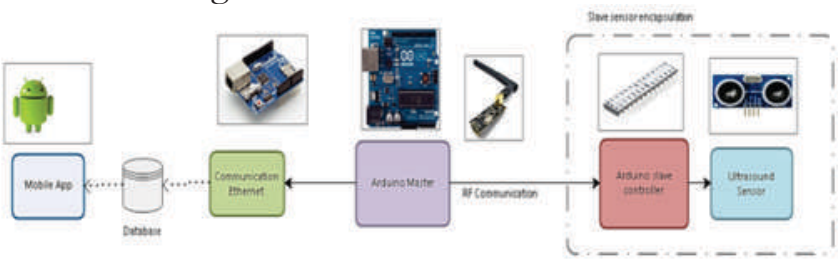

Figure 1. Block diagram of alternative solution. Source: own.

\subsection{Methodology}

Figure 2, shows the stages of the proposed alternative solution and the flow of information among them.

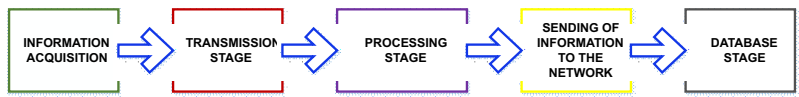

Figure 2. Alternative solution stages. Source: own.

\subsubsection{Acquisition of information:}

Ultrasonic sensors HCSRO4 were implemented and they allowed the measurement to be made, as they are capable of detecting objects and calculating the distance at which they are within a range from $3 \mathrm{~cm}$ to $450 \mathrm{~cm}$, using a frequency of $40 \mathrm{KHz}$ [18] with an accuracy of $3 \mathrm{~mm}$ [19].

\subsubsection{Transmission stage:}

For this stage, NRF2401 RF modules were used and configured as slaves and just leaving one as master, they communicate with each other through the SPI (Serial Peripheral Interface) protocol, whose structure is defined in Figure 3.

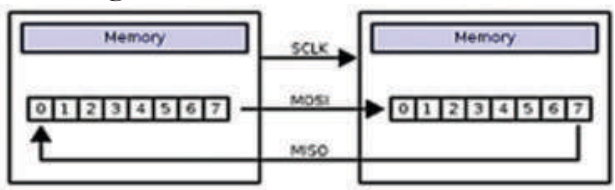

Figure 3. SPI General Structure, [20].

The modules integrate an RF transceiver (transmitter + receiver) at a frequency between $2.4 \mathrm{GHz}$ and 2.5 $\mathrm{GHz}$; a free band for free use. The modules have a power accuracy of $4 \mathrm{~dB}[21]$. 


\subsubsection{Processing stage:}

It is carried out through the ARDUINO microcontroller, which aims at processing the information and data delivered by the already stated sensors in order to determine by means of an algorithm whether the parking space is empty or occupied.

\subsubsection{Transmission of information to the network:}

Once the information is received, it is processed by the controller and sent to a mobile platform available to the user to know the parking status.

\subsubsection{Database stage:}

A SQL database model is used, through phpmyadmin (?), a model was developed and it has 5 related tables as shown in Figure 4.



Figure 4. PhpMyAdmin Tables. Source: own.

In the first one, it is possible to observe the relationship between the location of the parking space and the user, in the second one is found the types of users that there can be, either Premium or normal, when talking about Premium features, we are talking about a customer who can book a parking space and who unlike a normal user, does not have to deal with advertising.

In the third one, it is found the registered users, this chart is important because it makes data analysis possible, marketing and definition of new parameters, in order to innovate and improve the application for the user.

In the fourth one Bogota's localities are displayed, since the application makes it possible to filter available parking lots and parking spaces in areas surrounding the destination. The fifth and last chart correlates the location of the parking spaces provided by the parking lots.
The database and the mobile application (Android) are used to establish the communication, and the database is called through services, such as: "RESTful", "get" and "post" which is done in Php, as shown in Figure 5.

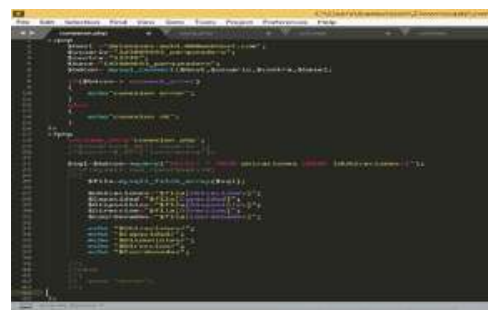

Figure 5. "get" y "post" Structure in PHP. Source: own.

\subsection{Tests}

In order to offer the user a differential factor when comes to quality of service, tests for the analysis of quality parameters or QoS were carried out (Table 4); in addition, in Figure 6, the implementation of the already stated tests is illustrated in the stages described in Figure 1.

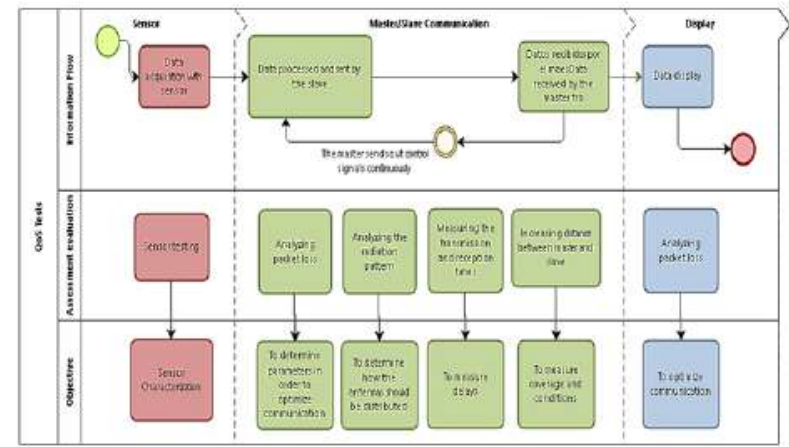

Figure 6. QoS tests by sections. Source: own.

\begin{tabular}{|l|l|}
\hline TEST & OBJECTIVE \\
\hline Distance measuring & Sensor characterization \\
\hline $\begin{array}{l}\text { Varying the number of attempts to } \\
\text { send control and transmission messages }\end{array}$ & $\begin{array}{l}\text { Measuring and varying the number of } \\
\text { retries and validating their behavior }\end{array}$ \\
\hline Analyzing packet loss & Determining optimal communication parameters \\
\hline Changing the transmission speed & Setting the ideal transmission speed. \\
\hline $\begin{array}{l}\text { Increasing the distance between } \\
\text { masters and slaves }\end{array}$ & $\begin{array}{l}\text { Setting themaximum operating distance } \\
\text { without losing information. }\end{array}$ \\
\hline Adding obstacles & $\begin{array}{l}\text { Determining itsfunctioning in the presence of } \\
\text { obstacles and suggesting possible new locations. }\end{array}$ \\
\hline
\end{tabular}

Table 4. Service quality testing. Source: own.

\section{Results}

The sensors were assembled as shown in Figures 7 and 8.

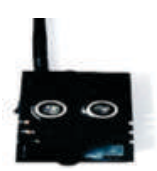

Figure 7. Sensor encapsulation Source: own. 


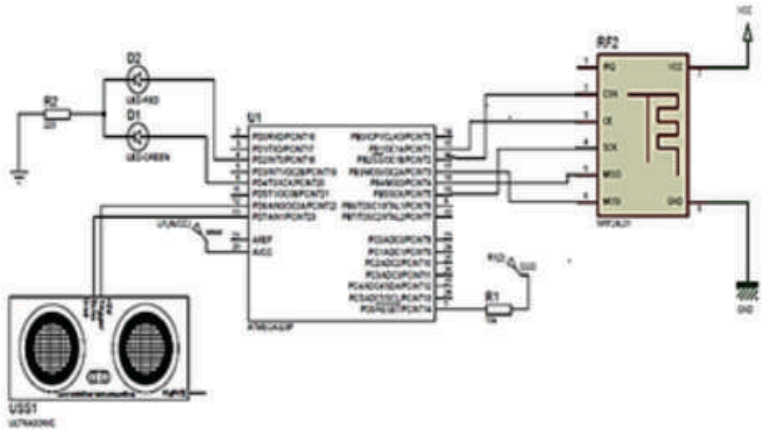

Figure 8. Encapsulation assembly. Source: own.

\subsection{Information acquisition stage:}

The sensor emits a series of ultrasound waves and measures the return time. With this data, a location can be calculated using equation (1):

$$
\text { Distance }=\frac{\text { speed of sound in air x time }}{2}
$$

Figure 9, shows the characterized operation of the sensor and its closeness to the predefined distances by programming.

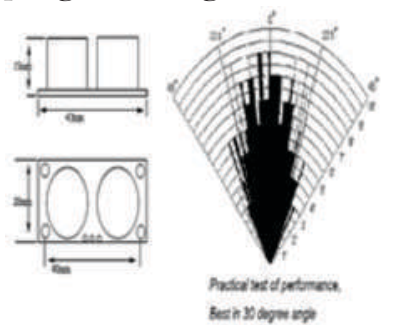

Sensor's total operating range
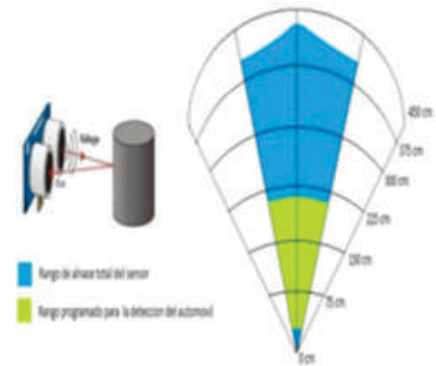

Programmed range for car detection
Figure 9. Sensor characterization. Source: own.

As it is shown, this functioning range ensures that the vehicle will be identified at distances no greater than 4.5 m. A total of 2,161 tests were performed, which are illustrated in Figure 10, where the operating distance was measured with a concrete surface located at 2 and 4 meters away.



Figure 10. Sensor test at two and four-meter distances. Source: own.
However, the behavior of the sensor is illustrated in more detail in Figure 11.

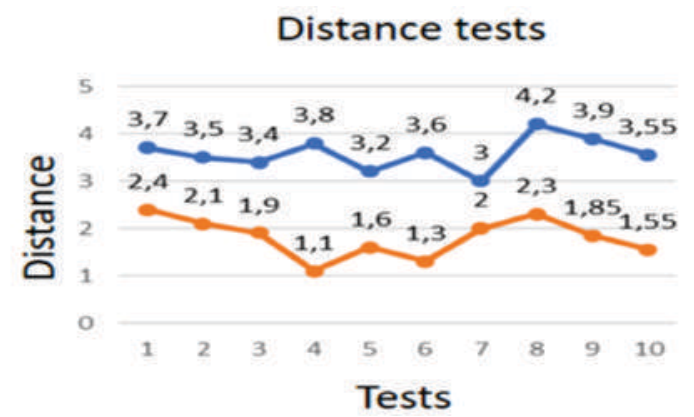

Figure 11. Sensor test at two and four-meter distances with less data to identify its behavior. Source: own.

It was established as a quality of service parameter that the sensors must be installed at a distance of more than $30 \mathrm{~cm}$ between them.

\subsection{Transmission stage:}

The $\mathrm{RF}$ module antenna radiation pattern was


shows a similar operation to the $2.4 \mathrm{GHz}$ Wi $\mathrm{Fi}$ antennas (Common in homes).

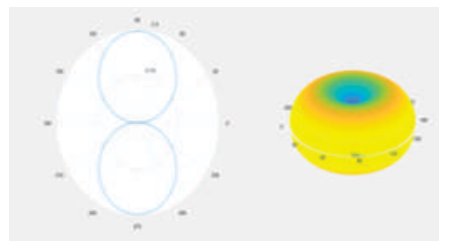

Figure 12. RF antenna's radiation pattern Source: own.

A scan was performed on packets sent from the Ethernet Shield of the master Arduino, resulting in the data shown in Figure 13. Based on the captured data, their IP and TCP headers can be determined, as shown in Tables 5 and 6.

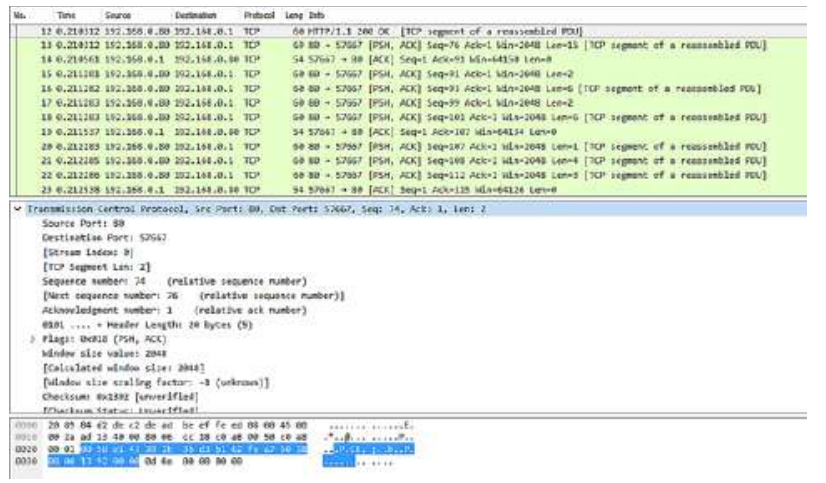

Figure 13. Wireshark screenshot. Source: own. 


\begin{tabular}{|l|l|}
\hline Destination port: & 57667 \\
\hline Header length: & 20 Bytes \\
\hline Flags: & ACK, PSH, FIN \\
\hline Urgent pointer & 0 \\
\hline
\end{tabular}

Table 5. Acquired data from the TCP frame Source: own.

\begin{tabular}{|l|l|}
\hline Type of service: & \multicolumn{1}{|c|}{ Routine } \\
\hline Fragment: & $\begin{array}{l}\text { The message does not } \\
\text { fragment because of its } \\
\text { small amount of data. } \\
\text { oXoo }\end{array}$ \\
\hline Life span: & 128 \\
\hline Protocol: & TCP \\
\hline Checksum: & Hash \\
\hline Direction Ip Origen: & 192.168 .0 .80 \\
\hline Direction Ip Destine & 192.168 .0 .1 \\
\hline
\end{tabular}

Table 6. Acquired data from the IP frame. Source: own.

The CSo or default oXoo has best-effort forwarding features.

For this reason, the Internet was designed on the basis of a "best-effort" service, that is, without any guarantee of service quality.

On the other hand, tests were performed by varying the transmission speed of 100 data packets sent by the Arduino slaves to determine the proportion in which those packets are lost as the speed increases; the data are shown in Figure 14 below.

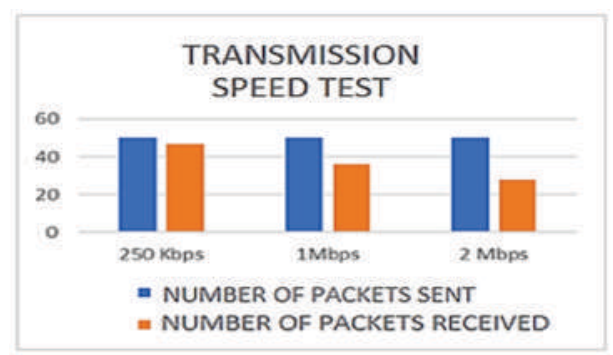

Figure 14. Transmission speed test. Source: own.

\subsection{Mobile APP:}

Finally, a mobile application was developed so as to establish an environment that facilitates the user's direct interaction with the parking lot; there the end user will be able to check: rates, structure and location of the parking lot, number of parking spaces and their availability. When selecting a destination parking lot, the user can make use of Google Maps for routing; if he has a premium account, a booking service is available for the parking space chosen by the user in order to make it easier for him to find an available parking space near or at your destination, as shown in Figure 15.

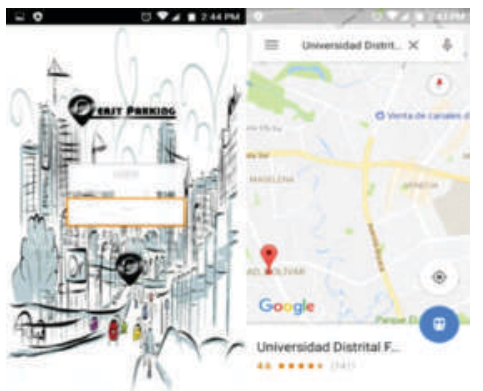

Figure 15. Mobile App. Source: own.

\section{Conclusions}

All in all, the sensor's operating distance was adequately guaranteed, as it has the appropriate distance in order that external disturbances and surrounding sensors do not affect the quality of the recorded measurements. The roof-to-car and sensor-to-sensor distances were established based on the technical specifications provided by the sensor supplier, these measurements were verified by trial and error tests; taking the given specifications as a reference, the sensors were located in a stability zone.

It was determined that, even though the frames sent by the Ether net module do not have any priority to provide better QoS, the tests carried out in Figure 14 -at speeds of $250 \mathrm{Kbps}, 1 \mathrm{Mbps}$ and $2 \mathrm{Mbps}$-guarantee that the bandwidth is higher than that required by the system to transmit the captured information.

It was shown that the antennas' position must have a line of sight propagation, since not having one can cause loss of packets or connection between them; this is due to two factors: the radiation pattern of the antenna and the power that is delivered to it. The radiation factor shows that there is a direction in which communication is not possible; in turn, the power delivered to the antenna should not be too high in order to avoid interference in the data transmission in surrounding sensors.

Using NRF240 1 wireless RF modules, in master/ slave mode and using Arduino development cards, correct communication and information exchange was achieved at low error rates between sensor nodes. This guarantees the reliability of the parking system's operation, as shown in Figure 14.

On the other hand, as work for the future, the implementation of the prototype in more than just one parking lot is proposed so as to offer greater selection possibilities to the user at the same time. Although the approximate cost per sensor (prototype) is COP $\$ 40,000$, this integration would reduce costs when purchasing raw materials in bulk and at the same time it 
would make certain features of the application more robust and have real functionality. As an example, the fact of separating parking spaces and going beyond being an option in the application would be considered. That is to say, a synergy between infrastructure and accessibility must be guaranteed, generating an even greater impact than would be obtained with the basic application.

\section{Acknowledgements}

We express our gratitude to ROMA research group, which contributed to the development and sustenance of this research article. As well as the SciBas group for their widely guidance and advice.

\section{References}

[1] INRIX, "INRIX 2016 Global Traffic Scorecard”, 2018. [Online]. Available at: http://inrix.com/resources/inrix-2016global-traffic-scorecard/.

[2] INRIX, "INRIX Global Traffic Scorecard", 2018 . [Online]. Available at: http://inrix.com/scorecard/\#.

[3] Electrónica Básica, "Radio frecuencia seguridad”, 2018. [Online]. Available at: http://www.electronica-basica.com/radiofrecuencia-seguridad.html.

[4] El Tiempo, "Tecnología, aliada en centros comerciales de Medellín”, 2018. [Online]. A v a i l a b l e a t : http://www.eltiempo.com/archivo/document o/CMS-15599636.

[5] S. Castellanos-Rojas, "Sistema de asistencia y monitoreo para un parqueadero en entorno abierto usando visión artificial", thesis, 2018.

[6] C. Córdoba and B. Plazas, "Prototipo de control y monitoreo para parqueaderos vehiculares", Revista Tekhnê, vol. 12, no. 1, 2015, pp. 67-72.

[7] W. Park, B. Kim, D. Seo, D. Kim and K. Lee, "Parking space detection using ultrasonic sensor in parking assistance system", Intelligent Vehicles Symposium, 2008 IEEE, $2008, \quad p p .1039-1044$. https://doi.org/10.1109/IVS.2008.4621296.

[8] N. Hanif, M. Badiozaman and H. Daud, "Smart parking reservation system using short message services (SMS)", Intelligent and Advanced Systems (ICIAS), 2010 International Conference, 2010, p p. $1-5$. https://doi.org/10.1109/ICIAS.2010.5716179.
Eglobalt, "Automatización de estacionamientos", 2012. [Online]. Available at: http://www.eglobalt.com/parking.php.

[10] G. Yan, W. Yang, D. Rawat and S. Olariu, "SmartParking: A Secure and Intelligent Parking System”, IEEE Intell. Transp. Syst. Mag., vol. 3, no. 1, 2011 , pp. 18-30. https://doi.org/10.1109/MITS.2011.940473.

[11] C. Roman, R. Liao, P. Ball, S. Ou and M. de Heaver, "Detecting On-Street Parking Spaces in Smart Cities: Performance Evaluation of Fixed and Mobile Sensing Systems", IEEE Transactions on Intelligent Transportation $\mathrm{S}$ y $\mathrm{s} \mathrm{t}$ e $\mathrm{m} \mathrm{s}$, $\begin{array}{llll}2 & 0 & 1 & 8\end{array}$. https://doi.org/10.1109/TITS.2018.2804169

J. Fang, A. Ma, H. Fan, M. Cai and S. Song, "Research on smart parking guidance and parking recommendation algorithm", 8th IEEE International Conference on Software Engineering and Service Science (ICSESS), Beijing, China, 2017, pp. 209-212. https://doi.org/10.1109/ICSESS.2017.83428 $\underline{98 .}$

[13] N. Rakshit, S. Som, V. Tuli and S. K. Khatri, "Smart and connecting city parking Leveraging lot", International Conference on Infocom Technologies and Unmanned Systems (Trends and Future Directions) (ICTUS), D u b a i, 2017 , p p. $584-587$. https://doi.org/10.1109/ICTUS.2017.82860 $\underline{76 .}$

[14] J. Shi, L. Jin, J. Li and Z. Fang, "A smart parking system based on NB-IoT and third-party payment platform”, 17 th International Symposium on Communications and Information Technologies (ISCIT), Cairns, Q L D , 2017 , p p . $1-5$. https://doi.org/10.1109/ISCIT.2017.826123 $\underline{5 .}$

[15] A. Feeney, L. Kang and S. Dixon, "High Frequency Measurement of Ultrasound using Flexural Ultrasonic Transducers", IEEE Sensors Journal, 2018 . https://doi.org/10.1109/JSEN.2018.2835146

[16] R. Neco García, O. Reinoso García and N. García Aracil, "Apuntes de sistemas de control. Alicante: ECU”, 2013. pp. 4.

[17] M. De Paula, I. Carlucho, A. Rozenfeld and G. G. Acosta, "Modelado e identificación de vehículos móviles usando modelos de baja 
complejidad basados en datos", IEEE Biennial Congress of Argentina (ARGENCON), Buenos Aires, Argentina, $2016, \quad$ p p . $1-6$. https://doi.org/10.1109/ARGENCON.2016.7585 $\underline{272}$

[18] Electronilab, "Sensor de Distancia de Ultrasonido HC-SRo4", 2018. [Online]. A v a i l a ble a t : https://electronilab.co/tienda/sensor-dedistancia-de-ultrasonido-hc-sro4.

[19] Mouser, "Ultrasonic Ranging Module HC Sro4", 2018. [Online]. Available at: https://www.mouser.com/ds/2/813/HCSRo 4-1022824.pdf.

[20] K. Navarro, "¿Cómo funciona el protocolo SPI?", 2014. [Online]. Available at: http://panamahitek.com/como-funciona-elprotocolo-spi/.

[21] Sparkfun, "Nrf24lo1+ Single Chip 2.4GHz Transceiver", 2018. [Online]. Available at: https://www.sparkfun.com/datasheets/Comp onents/SMD/nRF24L01Pluss_Preliminary_ Product_Specification_v1_o.pdf. 